\title{
Association between sequence variants in panicle development genes and the number of spikelets per panicle in rice
}

\author{
Su Jang ${ }^{1}$, Yunjoo Lee ${ }^{1}$, Gileung Lee ${ }^{1}$, Jeonghwan Seo ${ }^{1}$, Dongryung Lee ${ }^{1}$, Yoye Yu', Joong Hyoun Chin ${ }^{2 *}$ \\ and Hee-Jong Koh ${ }^{1 *}$ (D)
}

\begin{abstract}
Background: Balancing panicle-related traits such as panicle length and the numbers of primary and secondary branches per panicle, is key to improving the number of spikelets per panicle in rice. Identifying genetic information contributes to a broader understanding of the roles of gene and provides candidate alleles for use as DNA markers. Discovering relations between panicle-related traits and sequence variants allows opportunity for molecular application in rice breeding to improve the number of spikelets per panicle.

Results: In total, 142 polymorphic sites, which constructed 58 haplotypes, were detected in coding regions of ten panicle development gene and 35 sequence variants in six genes were significantly associated with panicle-related traits. Rice cultivars were clustered according to their sequence variant profiles. One of the four resultant clusters, which contained only indica and tong-il varieties, exhibited the largest average number of favorable alleles and highest average number of spikelets per panicle, suggesting that the favorable allele combination found in this cluster was beneficial in increasing the number of spikelets per panicle.

Conclusions: Favorable alleles identified in this study can be used to develop functional markers for rice breeding programs. Furthermore, stacking several favorable alleles has the potential to substantially improve the number of spikelets per panicle in rice.
\end{abstract}

Keywords: Rice, Single nucleotide polymorphisms, Haplotype, The number of spikelets per panicle, Panicle-related traits, Candidate gene association analysis

\section{Background}

In rice, the number of spikelets per panicle (SPP) is an important agronomic characteristic that has a strong impact on yield. SPP is determined by several panicle-related traits, such as the number of primary branches per panicle (PB), the number of secondary branches per panicle $(\mathrm{SB})$, and panicle length (PL). Improving the balance between paniclerelated traits is needed to optimize SPP [1]. Panicle-related traits are controlled by a range of panicle development genes such as ABERRANT PANICLE ORGANIZATION 1 (APO1) [2], ABERRANT PANICLE ORGANIZATION 2

\footnotetext{
* Correspondence: jhchin@sejong.ac.kr; heejkoh@snu.ac.kr

${ }^{2}$ Graduate School of Integrated Bioindustry, Sejong University, 209,

Neungdong-ro, Gwangjin-gu, Seoul 05006, South Korea

'Department of Plant Science, Plant Genomics and Breeding Institute,

Research Institute for Agriculture and Life Sciences, Seoul National University, Seoul 08826, South Korea
}

(c) The Author(s). 2018 Open Access This article is distributed under the terms of the Creative Commons Attribution 4.0 International License (http://creativecommons.org/licenses/by/4.0/), which permits unrestricted use, distribution, and reproduction in any medium, provided you give appropriate credit to the original author(s) and the source, provide a link to the Creative Commons license, and indicate if changes were made. The Creative Commons Public Domain Dedication waiver (http://creativecommons.org/publicdomain/zero/1.0/) applies to the data made available in this article, unless otherwise stated.
ERECT PANICLE 1 (DEPI) [5], GRAIN NUIMBER, PLANT HEIGHT, AND HEADING DATE 8 (GHD8) [6], HEADING DATE 1 (HD1) [7], FLORAL ORGAN NUMBER 1 (FON1) [8], SHORT PANICLE 1 (SP1) [9], LAX PANICLE 1 (LAX1) [10], and MONOCULM 1 (MOC1) [11]. A better understanding of the roles and influence of these genes is needed to increase SPP in commercial rice varieties. It is important to identify DNA sequence variation of genes controlling agronomic traits and discover beneficial sequence variants for some traits in that they allow opportunity for molecular application in rice breeding to improve target traits [12].

Candidate gene association analysis investigates the relation between polymorphic sites in genes which are involved in specific phenotypes and phenotypic variations, thereby facilitating identification of causative sequence 
variants for particular characteristics leading to phenotypic variation. Candidate gene association analysis was previously used to identify novel beneficial polymorphic sites related to important agronomic traits. For example, some functional mutations of GHD7 that were not identified in an earlier study were detected using General Linear Model (GLM) association analysis [13, 14] and in a separate study, Wei et al. [15] found that five INDELs in the coding region of $H D 1$ were significantly associated with flowering date in rice.

Functional markers that are directly derived from polymorphic sites within the genes responsible for variations in the target trait can be used directly for markerassisted breeding as the most effective marker. Prior to identifying the favorable alleles that can be used as resource of functional marker, genetic information about genes, such as level of DNA polymorphism and linkage disequilibrium (LD), are required for successful marker development [16].

The objectives of this study were to (1) identify novel sequence variants in the coding regions of panicle development genes which were previously reported to control panicle development and investigate genetic information, (2) identify sequence variants associated with paniclerelated traits, including $\mathrm{PL}, \mathrm{PB}$, and $\mathrm{SB}$, and (3) find combinations of favorable alleles for each trait that could contribute to increasing SPP in rice.

\section{Methods}

\section{Plant materials and phenotypic data analysis}

Panicle size of 205 rice varieties were measured and 45 rice varieties were selected using proportionate stratified sampling to ensure that phenotypic variation for panicle size was fully represented (Additional file 1). All plant materials were grown in the experimental field of Seoul National University in Suwon, Korea $\left(37^{\circ} \mathrm{N}\right.$ latitude). Selected 45 varieties originated from 11 countries and were of three types: japonica $(N=22)$, indica $(N=18)$, and tong-il $(N=5)$ (Additional file 2). Panicle-related traits, including PL, PB, SB, and SPP, were measured using the longest panicle from stem of an individual plant. Three to five replicate measurements were performed in 2013 and 2014. All statistical analysis for phenotypic values was performed using IBM SPSS STATISTICS 21.

\section{DNA extraction, PCR amplification, and sequencing}

Fresh young leaves were harvested from each field-grown plant and stored at $-80{ }^{\circ} \mathrm{C}$. Genomic DNA was extracted according to the modified cetyl-trimethyl ammonium bromide (CTAB) method [17]. To identify nucleotide polymorphisms in the coding regions of ten genes associated with panicle development, 48 Primers for sequencing were designed based on Nipponbare reference genome using Primer3plus [18]. Four allele-specific primers for
MOC1 were designed based on sequence data of 8 representative varieties using BatchPrimer3 [19] (Additional file 3). Reactions were performed in a total volume of $50 \mu \mathrm{l}$ and contained $100 \mathrm{ng}$ genomic DNA, $2.5 \mathrm{nM}$ each primer, $2.5 \mathrm{mM}$ dNTPs, $5 \mu \mathrm{l} 10 \times$ buffer, and 0.25 unit Ex Taq (Takara). PCR was performed using a DNA Engine Tetrad 2 Thermal Cycler (Bio-Rad) with the following parameters: $95^{\circ} \mathrm{C}$ for $10 \mathrm{~min}, 30$ cycles of amplification $\left(45 \mathrm{~s}\right.$ at $95^{\circ} \mathrm{C}, 45 \mathrm{~s}$ at the appropriate $\mathrm{Tm}$ for each primer pair, and $72{ }^{\circ} \mathrm{C}$ for an appropriate time for product length), and final extension at $72{ }^{\circ} \mathrm{C}$ for $10 \mathrm{~min}$. PCR amplicons were separated by gel electrophoresis on $1.5 \%$ agarose gels containing ethidium bromide in $0.5 \times \mathrm{TBE}$ buffer, and visualized using a CDU-2126 Dual UV Trans illuminator (Core Bio System). PCR products were sequenced after purification using a Gel \& PCR Purification kit (Inclone Biotech). Sanger sequencing was performed using the BigDye Terminator v3.1 Cycle Sequencing kit with the subsequent analysis on an ABI3730XL automated DNA analyzer (Applied Biosystems).

\section{DNA sequence analysis}

Coding and non-coding regions of 10 genes, including APO1, APO2, GN1a, DEP1, GHD8, HD1, FON1, SP1, $L A X 1$, and $M O C 1$ were identified by comparison with annotated DNA sequences from the Rice Annotation Project Database IRGSP-1.0 [20]. Multiple sequence alignment was performed using Clustal W [21] and further edited using Bioedit 7.2.0 [22] (Additional file 4). DnaSP 5.0 [23] was used to analyze nucleotide diversity $(\pi)$. Neutrality tests were conducted for calculating Tajima's $D$ [24] by the same program. Haplotype networks separated by mutational steps, including INDELs, were constructed using TCS 1.21 [25]. Tassel 5.2.15 [26] was used to construct UPGMA (Unweighted Pair Group Method with Arithmetic Mean) trees and calculate LD between pairs of polymorphic sites. Only common alleles were used for LD analysis, and SNPs with minor allele frequency (MAF) less than 0.05 were not included.

\section{Population structure and candidate gene association analysis}

Population structure was estimated from 122 SNPs using STRUCTURE 2.3.4 [27]. Ten replicated runs were performed with the following setup: population number of $2-7$, burn-in of 50,000, MCMC replication of 100,000, and model for admixture and correlated allele frequencies. The most probable number for $K$ was calculated according to Evanno's methods [28] using Structure Harvester 0.6.94 [29]. Ten Q-matrices obtained from STRUCTURE were combined and permutated using CLUMPP 1.1.2 [30]. Associations between each of the phenotypic values and DNA polymorphisms with MAF $>0.05$ were analyzed using GLMs in Tassle 5.2.15. 


\section{Results}

\section{Nucleotide diversity}

Eight representative varieties were sequenced to find sequence variant in coding region of MOC1 gene (Additional file 1). Only one non-synonymous SNP (CG) located at 131 bp was detected by comparison alignment with the Nipponbare sequence as reference
(Additional file 5A) and allele-specific primer sets were developed to assess this SNP. Result of SNP genotyping for MOC1 was presented in Additional file 5B. The MOC1-C allele was detected in 35 varieties and mainly distributed in japonica varieties (62.8\%), and the MOC1$\mathrm{G}$ allele was observed in ten varieties, including eight varieties of indica and two tong-il. A total length of

Table 1 Summary of DNA variation in nine genes involved in panicle development

\begin{tabular}{|c|c|c|c|c|c|c|c|}
\hline Gene (bp) & Group & No. of nucleotide substitutions & No. of INDELS & $\pi \times 10^{-3}$ & $h$ & $H d$ & D \\
\hline \multirow[t]{4}{*}{ LAX1 (648) } & Total & 1 & 0 & 0.76 & 2 & 0.491 & - \\
\hline & Indica & 1 & 0 & 0.66 & 2 & 0.425 & - \\
\hline & Japonica & 1 & 0 & 0.14 & 2 & 0.091 & - \\
\hline & Tong-il & 1 & 0 & 0.62 & 2 & 0.400 & - \\
\hline \multirow[t]{4}{*}{ APO1 (1299) } & Total & 12 & 3 & 2.02 & 3 & 0.533 & -0.146 \\
\hline & Indica & 12 & 3 & 3.6 & 3 & 0.667 & 1.135 \\
\hline & Japonica & 0 & 0 & - & - & - & - \\
\hline & Tong-il & 2 & 1 & 0.62 & 2 & 0.400 & -0.973 \\
\hline \multirow[t]{4}{*}{ APO2 (1170) } & Total & 13 & 0 & 4.83 & 3 & 0.536 & $2.755^{* *}$ \\
\hline & Indica & 13 & 0 & 4.33 & 3 & 0.602 & 1.329 \\
\hline & Japonica & 0 & 0 & - & - & - & - \\
\hline & Tong-il & 11 & 0 & 3.76 & 2 & 0.400 & -1.200 \\
\hline \multirow[t]{4}{*}{ DEP1 (1281) } & Total & 19 & 1 & 2.78 & 9 & 0.723 & -1.251 \\
\hline & Indica & 9 & 0 & 2.38 & 7 & 0.854 & 0.647 \\
\hline & Japonica & 11 & 1 & 1.49 & 3 & 0.267 & -1.320 \\
\hline & Tong-il & 6 & 0 & 2.03 & 3 & 0.700 & -0.668 \\
\hline \multirow[t]{4}{*}{ FON1 (2985) } & Total & 14 & 0 & 2.05 & 6 & 0.764 & $2.820^{* *}$ \\
\hline & Indica & 6 & 0 & 0.99 & 4 & 0.731 & $2.321^{*}$ \\
\hline & Japonica & 12 & 0 & 2 & 3 & 0.552 & $2.812^{* *}$ \\
\hline & Tong-il & 10 & 0 & 1.34 & 2 & 0.400 & -1.193 \\
\hline \multirow[t]{4}{*}{ GHD8 (903) } & Total & 16 & 6 & 6.16 & 9 & 0.812 & 1.605 \\
\hline & Indica & 15 & 6 & 4.07 & 7 & 0.866 & -0.560 \\
\hline & Japonica & 11 & 1 & 1.54 & 3 & 0.495 & $-1.920^{*}$ \\
\hline & Tong-il & 11 & 3 & 7.13 & 3 & 0.800 & 1.527 \\
\hline \multirow[t]{4}{*}{ GN1a (1706) } & Total & 8 & 4 & 1.44 & 8 & 0.790 & 0.948 \\
\hline & Indica & 5 & 2 & 0.98 & 6 & 0.801 & 0.526 \\
\hline & Japonica & 6 & 3 & 1.26 & 4 & 0.557 & 0.895 \\
\hline & Tong-il & 3 & 2 & 1.06 & 2 & 0.600 & 1.573 \\
\hline \multirow[t]{4}{*}{ HD1 (1353) } & Total & 12 & 9 & 4.04 & 9 & 0.771 & $3.105^{* *}$ \\
\hline & Indica & 10 & 8 & 3.07 & 6 & 0.760 & 1.503 \\
\hline & Japonica & 11 & 4 & 4.11 & 4 & 0.686 & $3.050^{* * *}$ \\
\hline & Tong-il & 12 & 4 & 4.08 & 3 & 0.700 & -1.031 \\
\hline \multirow[t]{4}{*}{ SP1 (1881) } & Total & 20 & 3 & 2.11 & 7 & 0.679 & -0.436 \\
\hline & Indica & 7 & 0 & 1.33 & 4 & 0.696 & 0.756 \\
\hline & Japonica & 17 & 3 & 2.44 & 5 & 0.538 & -0.105 \\
\hline & Tong-il & 3 & 0 & 0.65 & 2 & 0.400 & -1.049 \\
\hline
\end{tabular}

$S$, Number of variable sites; $\pi$, Nucleotide diversity; $h$, Number of haplotypes; $H d$, Haplotype diversity; $D$, Tajima's $D$ 
coding region of $L A X 1$ is 649 bp and only one SNP (TG) which caused change of amino acid was detected at 349 bp (Additional file 5C). The LAX1-T and LAX1-G alleles were detected in 18 and 27 varieties, respectively. Of the varieties carrying the $L A X 1-\mathrm{T}$ allele, $75 \%$ were of the japonica type, and $72 \%$ of the varieties carrying the LAX1-G allele were of the indica type. For the other eight panicle development genes, values of $\pi$ (nucleotide diversity) ranged from $1.44 \times 10^{-3}$ (GN1a) to $6.16 \times 10^{-3}$ (GHD8). $\pi$ for APO1, APO2, DEP1, and GHD8 were higher in indica than in japonica varieties, whereas $\pi$ for
FON1, GN1a, HD1, and SP1 were higher in japonica than in indica.

\section{Haplotype diversity}

In total, 58 haplotypes were constructed based on polymorphic sites in coding regions of panicle development genes. $H d$ (haplotype diversity) for eight of the ten genes (all except MOC1 and LAX1) ranged from 0.533 (APO1) to 0.812 (GHD8) (Table 1) and was higher in indica than in japonica varieties. Haplotypes for DEP1, GN1a, HD1, and GHD8 genes were known from previous studies $[5,15,31$,

a

\begin{tabular}{|c|c|c|c|c|c|c|c|c|c|c|c|c|c|c|c|c|}
\hline \multirow{2}{*}{\multicolumn{2}{|c|}{$\begin{array}{l}\text { Region } \\
\text { Position }\end{array}$}} & \multicolumn{7}{|c|}{ EXON 1} & \multicolumn{8}{|c|}{ EXON 2} \\
\hline & & g & is & 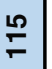 & है & 总 & స్ & ह̊ & 年 & 员 & 吕 & छ̊ & 号 & Бू & 용 & $\stackrel{\infty}{\frac{\infty}{二}}$ \\
\hline \multicolumn{2}{|c|}{ Nip } & A & $\mathbf{A}$ & $\mathbf{A}$ & $G_{-}$ & c & $\bar{c}$ & $C$ & $\mathbf{A}$ & G & & & $C$ & $T$ & $\mathrm{C}$ & \\
\hline pe 1 & $A P O 1-2$ & A & A & A & G & $\underline{c}$ & $\mathrm{C}$ & $\mathrm{C}$ & $\mathrm{A}$ & G & - & & $C$ & & $\mathrm{C}$ & \\
\hline Type 2 & APO1-3 & A & A & \begin{tabular}{l|l} 
\\
\end{tabular} & G & $\bar{c}$ & c & $\mathrm{G}$ & $\mathrm{A}$ & $G$ & & $9 \mathrm{del}$ & & $\mathrm{T}$ & $C$ & \\
\hline jpe 3 & $07-$ & $G$ & $G$ & $G$ & $c$ & & A & C & $G$ & A & 9 ins & & $A$ & $\mathrm{~A}$ & $\mathrm{G}$ & \\
\hline
\end{tabular}

b

\begin{tabular}{|c|c|c|c|c|c|c|c|c|c|c|c|c|c|c|}
\hline \multirow{2}{*}{\multicolumn{2}{|c|}{$\begin{array}{l}\text { Region } \\
\text { Position }\end{array}$}} & \multicolumn{7}{|c|}{ EXON 1 } & \multicolumn{5}{|c|}{ EXON 2} & \multirow{2}{*}{ 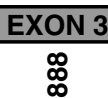 } \\
\hline & & $\stackrel{\infty}{\uparrow}$ & $\bar{\infty}$ & $\widehat{\infty}$ & ৪ & タ & ণ & 胥 & $\frac{1}{q}$ & $\stackrel{\text { டூ }}{9}$ & $\stackrel{\text { L }}{\circ}$ & 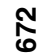 & 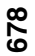 & \\
\hline \multicolumn{2}{|c|}{ Nip } & A & A & G & A & G & G & $\bar{G}$ & C & G & C & $T$ & G & C \\
\hline Type 1 & APO2-2 & A & A & $\mathrm{G}$ & A & $\mathrm{G}$ & G & G & $\mathrm{C}$ & $\bar{G}$ & C & $\mathrm{T}$ & $\bar{G}$ & C \\
\hline \multirow{2}{*}{ Type 2} & APO2-3 & $\mathrm{C}$ & $\bar{G}$ & $\bar{A}$ & $\bar{G}$ & $\bar{A}$ & $\bar{G}$ & T & $\bar{G}$ & $\bar{A}$ & $T$ & G & $\bar{T}$ & C \\
\hline & $\overline{A P O 2-1}$ & $\bar{C}$ & $\bar{G}$ & $\bar{A}$ & $\bar{G}$ & $\bar{A}$ & $\bar{A}$ & $\bar{T}$ & $\bar{G}$ & $\bar{A}$ & $\bar{T}$ & $\bar{G}$ & $\bar{T}$ & $\mathrm{~T}$ \\
\hline
\end{tabular}

C

\begin{tabular}{|c|c|c|c|c|c|c|c|c|c|c|c|c|c|c|c|}
\hline \multirow{2}{*}{\multicolumn{2}{|c|}{$\begin{array}{l}\text { Region } \\
\text { Position }\end{array}$}} & \multicolumn{12}{|c|}{ EXON 1} & \multicolumn{2}{|c|}{ EXON 2} \\
\hline & & $\stackrel{\text { ㅁ }}{-}$ & 㐫 & Бू & ฟั & ర్రి & N & $\stackrel{\infty}{\kappa}$ & ชิ & 욤 & ஜ & 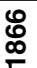 & $\frac{\hat{\sigma}}{2}$ & $\begin{array}{l}\text { \&్} \\
\text { đ. }\end{array}$ & $\begin{array}{l}\mathscr{O} \\
\mathscr{0}\end{array}$ \\
\hline \multicolumn{2}{|c|}{ Nip } & C & C & C & G & G & C & C & C & C & $\bar{A}$ & C & $T$ & C & $\mathrm{T}$ \\
\hline Type 1 & FON1-1 & C & C & C & $G$ & $G$ & C & C & C & $\mathrm{C}$ & $A$ & C & $\bar{T}$ & $\mathrm{C}$ & $\bar{T}$ \\
\hline Type 2 & FON1-3 & C & $C$ & $\mathrm{C}$ & $A$ & $G$ & $\mathrm{G}$ & C & $\mathrm{C}$ & C & $A$ & C & $T$ & $\mathrm{C}$ & $T$ \\
\hline \multirow{2}{*}{ Type 3} & FON1-2 & $T$ & $T$ & $\mathrm{C}$ & $\mathrm{A}$ & $G$ & $\mathrm{G}$ & $\mathrm{C}$ & $\mathrm{C}$ & $T$ & $\mathrm{G}$ & $T$ & $\mathrm{C}$ & $\mathrm{C}$ & $\mathrm{C}$ \\
\hline & FON1-4 & $T$ & $T$ & C & A & G & $\mathrm{G}$ & $\mathrm{C}$ & $\mathrm{G}$ & $T$ & $G$ & $T$ & $C$ & C & $\mathrm{C}$ \\
\hline Type 4 & FON1-5 & $T$ & $T$ & $T$ & $\mathrm{~A}$ & $G$ & $\mathrm{G}$ & $\mathrm{C}$ & $\mathrm{C}$ & $\mathrm{C}$ & $\mathrm{G}$ & $T$ & $\mathrm{C}$ & $\mathrm{T}$ & $\mathrm{C}$ \\
\hline Type 5 & FON1-6 & $\bar{T}$ & $\bar{T}$ & $T$ & $\bar{A}$ & $\bar{A}$ & $\bar{G}$ & $\mathrm{~T}$ & $\mathrm{C}$ & $\mathrm{C}$ & $\bar{G}$ & $\mathrm{~T}$ & $\mathrm{C}$ & $\bar{T}$ & $\mathrm{C}$ \\
\hline
\end{tabular}

d

\begin{tabular}{|c|c|c|c|c|c|c|c|c|c|c|c|c|c|c|c|c|c|c|c|c|c|}
\hline \multirow{2}{*}{\multicolumn{2}{|c|}{$\frac{\text { Region }}{\text { Position }}$}} & \multicolumn{2}{|c|}{ EXON 3} & \multicolumn{2}{|c|}{ EXON 4} & \multicolumn{16}{|c|}{ EXON 5} \\
\hline & & ભ్ల్ల & 占 & ৪ి & สู & ळ & 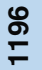 & & ષ્ণ & ס & ホ̃ & 옹 & 䓵 & స్ల్ర్ర & ஜ్ֶ & 옹 & 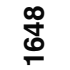 & $\underset{\varpi}{\leftarrow}$ & 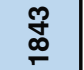 & $\begin{array}{l}\stackrel{\mathscr{Q}}{0} \\
\stackrel{0}{7}\end{array}$ & 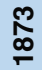 \\
\hline \multicolumn{2}{|c|}{ Nip } & 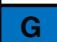 & C & - & $\bar{G}$ & $T$ & $\bar{G}$ & $C$ & G & A & - & G & A & G & C & G & - & $\mathrm{GG}$ & GAG & C & G \\
\hline ype 1 & $S P 1-1$ & $G$ & $C$ & - & $\bar{G}$ & $\bar{T}$ & $\bar{G}$ & $\mathrm{C}$ & $\bar{G}$ & $\bar{A}$ & - & $\bar{G}$ & $\bar{A}$ & $\bar{G}$ & $\bar{C}$ & $\bar{G}$ & - & GG & GAG & $\mathrm{C}$ & $\bar{G}$ \\
\hline Type 2 & $S P 1-3$ & $\mathrm{G}$ & C & 18 ins & G & $\mathrm{T}$ & C & G & C & A & - & G & A & G & $\mathrm{C}$ & $\mathrm{G}$ & - & $\mathrm{GG}$ & GAG & C & G \\
\hline Type 3 & $S P 1-4$ & G & C & 18 ins & G & T & C & G & C & $\mathrm{G}$ & $6 \mathrm{del}$ & A & C & C & $\mathrm{T}$ & $\mathrm{T}$ & $6 \mathrm{del}$ & $\mathrm{GG}$ & GAG & T & G \\
\hline Type 4 & $S P 1-6$ & G & C & $18 \mathrm{ins}$ & G & $T$ & $\bar{C}$ & G & C & $\mathrm{G}$ & $6 \mathrm{del}$ & A & C & C & $\mathrm{T}$ & $\mathrm{T}$ & $6 \mathrm{del}$ & $\mathrm{GG}$ & TTA & T & G \\
\hline Type 5 & SP1-7 & $G$ & $T$ & 18 ins & $\bar{G}$ & $\bar{T}$ & $\mathrm{C}$ & G & $\bar{T}$ & $G$ & $6 \mathrm{del}$ & A & $\mathrm{C}$ & C & $T$ & $T$ & $6 \mathrm{del}$ & CA & GAG & $T$ & $\bar{G}$ \\
\hline ype 6 & $S P 1-2$ & $A$ & $T$ & $18 \mathrm{ins}$ & $\mathrm{G}$ & $\bar{T}$ & $\mathrm{C}$ & G & $T$ & $G$ & $6 \mathrm{del}$ & A & C & C & $\mathrm{T}$ & $T$ & $6 \mathrm{del}$ & $\mathrm{GG}$ & GAG & $T$ & $C$ \\
\hline ype 7 & $S P 1-5$ & $\bar{A}$ & $\mathrm{C}$ & $18 \mathrm{ins}$ & $A$ & $\mathrm{C}$ & $\mathrm{C}$ & G & $\mathrm{C}$ & $\bar{G}$ & $6 \mathrm{del}$ & $\bar{A}$ & $\mathrm{C}$ & $\bar{C}$ & $T$ & $T$ & $6 \mathrm{del}$ & $\mathrm{GG}$ & GAG & $T$ & $\bar{G}$ \\
\hline
\end{tabular}

Fig. 1 Haplotype analysis of coding sequences. (a) APO1 (b) APO2 (c) DEP1 (d) FON1. Multiple sequence alignment was performed based on the Nipponbare rice reference sequence. Light blue boxes denote positions of non-synonymous polymorphisms. Nip, Nipponbare; Type, encoded protein type; ins, insertion; del, deletion 
32], but this study was the first to perform haplotype analysis for $A P O 1, A P O 2, F O N 1$, and SP1.

Three haplotypes were constructed for the APO1 coding region, designated $A P O 1-1$ to $A P O 1-3$, based on 15 polymorphic sites (Fig. 1a). Each haplotypes encoded three different protein types, based on three nonsynonymous SNPs and three INDELs. APO1-2 haplotype was most prevalent, being found in $60 \%$ of the 45 rice accessions and all japonica varieties carried this haplotype. By contrast, $A P O 1-1$ was found exclusively in four indica varieties. Tong-il type varieties primarily carried APO1-3 (Fig. 2a).

Three haplotypes were defined for the APO2 coding region based on 13 SNPs. APO2-1 and APO2-3 encoded identical proteins as the SNPs at 102 and 888 bp position were synonymous SNP (Fig. 1b). APO2-2 was the most frequent haplotype and was carried by 27 varieties, $77.8 \%$ of which were japonica. APO2-1 and APO2-3 were primarily found in indica varieties (Fig. 2b). Four tong-il type varieties carried $A P O 2-3$, and one carried APO2-2.

Six haplotypes encoding five different protein variants were found for FON1 (Fig. 1c). The most frequent haplotype was FON1-6, which was found in 14 varieties. FON1-1 and FON1-4 were detected in 13 and 11 varieties, respectively. Together, these three haplotypes were $84.4 \%$ of all accessions. FON1-2 and FON1-3 were minor haplotypes, each observed in only one variety (Fig. 2c). Four of the tong-il type varieties possessed the FON1-4 haplotype, and the remaining variety carried FON1-1.

Seven haplotypes, each encoding different protein variants, were identified for SP1. Different types of protein were predicted by eleven SNPs that led to change of eight amino acid and three INDELs. An 18 bp INDEL was identified specifically in the $S P 1-1$ haplotype, which was found only in japonica varieties (Fig. 1d). Haplotypes SP1-3 and SP1-6 were also only found in japonica. Conversely, SP1-2 and $S P 1-7$ were found exclusively in indica varieties. Four tongil type varieties carried the SP1-5 haplotype. The most prevalent haplotype was $S P 1-4$, which was found in 22 varieties. $S P 1-3, S P 1-6$, and $S P 1-7$ were minor haplotypes, each detected in only one variety (Fig. $2 \mathrm{~d}$ ).

\section{Phenotypic variations and candidate gene association analysis}

Phenotypic values from two field tests are presented in Additional file 6. Pearson correlation coefficients between panicle-related traits (PL, PB, SB, and SPP) were calculated using pairwise correlation analysis. $\mathrm{PL}$ showed significant positive correlation with $\mathrm{PB}, \mathrm{SB}$, and SPP. Both $\mathrm{PB}$ and SB were significantly positively correlated with SPP (Additional file 6). Considering population structure data (Additional file 2, 7 and 8), we conducted GLM association analysis to identify associations between

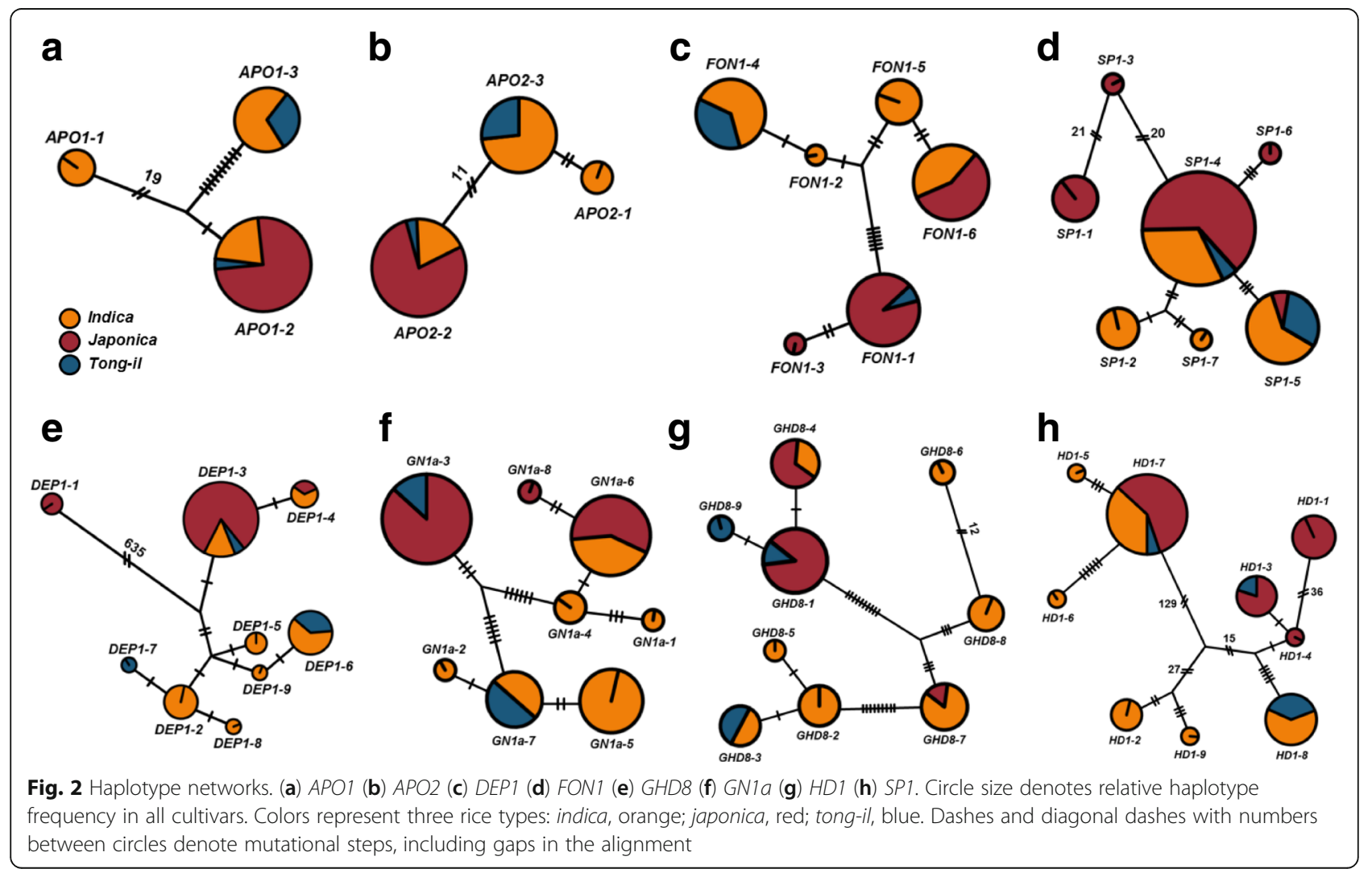


polymorphic sites of ten genes and three paniclerelated traits (PL, $\mathrm{PB}$, and $\mathrm{SB})$.

Ten SNPs and two INDELs in APO1 were significantly associated with SB in both field tests $(p<0.05)$. Eleven of the twelve polymorphisms, located at $40,57,537,546,627$, $765,795,850,951,1005$, and $1188 \mathrm{bp}$, were in complete LD $\left(r^{2}=1.0\right.$ and $p=0.0001$; Fig. 3a). The polymorphic site at position $948 \mathrm{bp}$ was detected differentially between the three haplotypes. Polymorphic sites in APO1 explained 18$19.1 \%$ and $11-12.3 \%$ of phenotypic variation in the first and second years, respectively (Table 2). Two SNPs in complete LD (102 and $888 \mathrm{bp}$ ) in $A P O 2$ were associated with SB in both field tests (Fig. 3b). These SNPs distinguished APO2-1 from the other haplotypes and explained $12.3 \%$ and $11.2 \%$ of SB variation in 2013 and 2014, respectively (Table 2). In DEP1, four SNPs, located at 41, 314, 683, and 970 bp position were significantly associated with PL (Fig. 3c). Three of these SNPs (314, 683, and $970 \mathrm{bp}$ ) were in complete LD and explained $3.9-8.9 \%$ of phenotypic variation in both years. The other SNP (41 bp) explained $3.8-5.3 \%$ of phenotypic variation in both years (Table 2).
One SNP in FON1, at position 1062, was significantly associated with PL (Fig. 3d) and explained 3.6-5.6\% of phenotypic variation in both field tests (Table 2). The G allele at this position was exclusively existed in FON1-4 haplotype. In $H D 1$, significant associations were detected between 14 polymorphic sites and phenotypic value of $\mathrm{PB}$ and SB (Fig. $3 \mathrm{e})$. Of these, ten polymorphic sites in complete LD (248, $249,440,466,469,487,512,661,1062$, and 1324 bp) explained $7-8.9 \%$ of phenotypic variation in PB in both years. An INDEL located at 1216 bp position was significantly associated with $\mathrm{PB}$ and $\mathrm{SB}$, explaining $5.7-6.8 \%$ of variation in $\mathrm{PB}$ and $7.8-18.5 \%$ of variation in SB in both field tests (Table 2). Two SNPs in SP1, located at 922 and 983 bp position were significantly associated with $\mathrm{SB}$ and were in complete LD (Fig. 3f). These polymorphic sites, found exclusively in the SP1-5 haplotype, explained $12.6-17 \%$ of variation in SB in both field tests (Table 2).

\section{Combination of favorable alleles}

Based on the estimates of the allelic effect on phenotypic variation for panicle-related traits, each of variants were

\section{a}

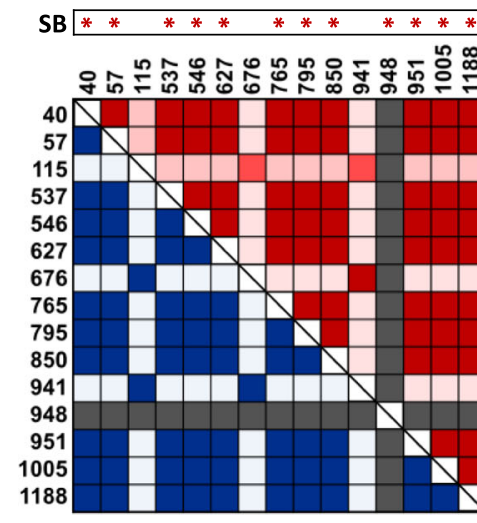

d

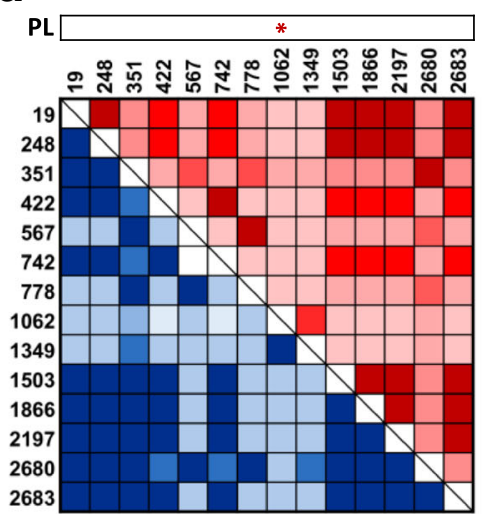

\section{b}

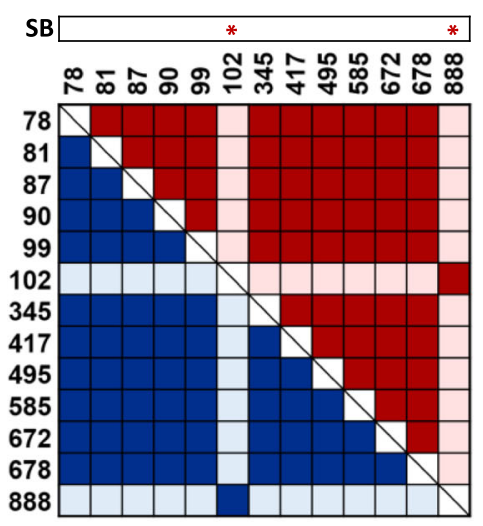

e

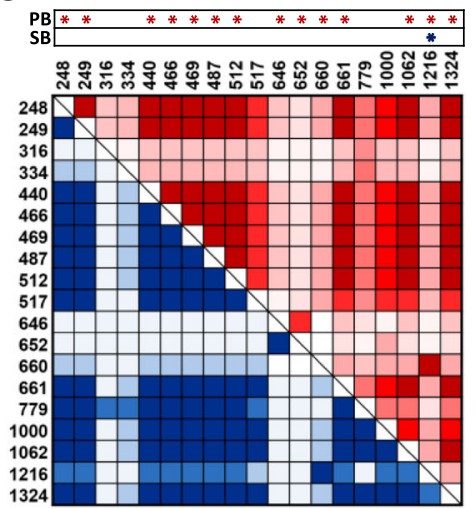

C

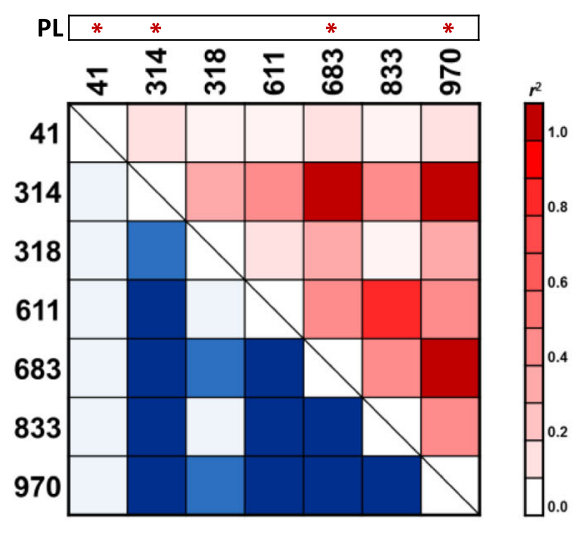

f

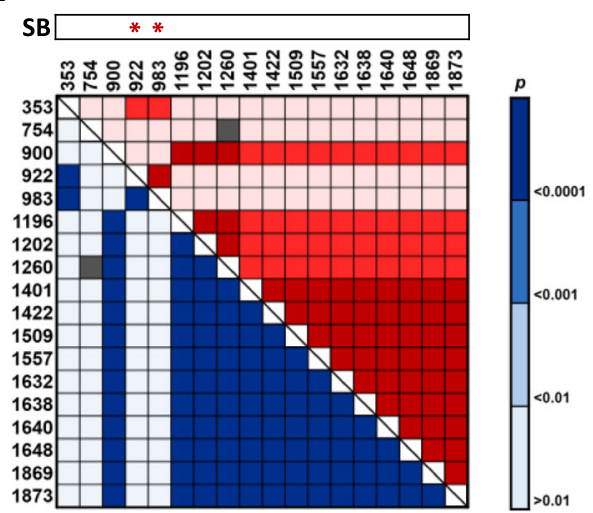

Fig. 3 Linkage disequilibrium patterns (MAF <0.05) and polymorphic sites associated with panicle-related traits in two field tests. (a) APO1 (b) APO2 (c) DEP1 (d) FON1 (e) HD1 (f) SP1. PL, panicle length; PB, the number of primary branches per panicle; and SB, the number of secondary branches per panicle. Asterisks indicate significant associations between sequence variants and phenotypic variations ( $P<0.05)$ 
Table 2 Sequence variants associated with three panicle-related traits in two field tests

\begin{tabular}{|c|c|c|c|c|c|c|c|c|c|c|c|c|}
\hline \multicolumn{7}{|l|}{2013} & \multicolumn{6}{|l|}{2014} \\
\hline \multirow[t]{2}{*}{ Site } & \multicolumn{2}{|l|}{$\mathrm{PL}$} & \multicolumn{2}{|l|}{ PB } & \multicolumn{2}{|l|}{ SB } & \multicolumn{2}{|l|}{$\overline{P L}$} & \multicolumn{2}{|l|}{ PB } & \multicolumn{2}{|l|}{ SB } \\
\hline & $p$ & $r^{2}$ & $p$ & $r^{2}$ & $p$ & $r^{2}$ & $p$ & $r^{2}$ & $p$ & $r^{2}$ & $p$ & $r^{2}$ \\
\hline \multicolumn{13}{|l|}{ APO1 } \\
\hline 11 sites in $L D^{a}$ & - & - & - & - & 0.001 & 0.180 & - & - & - & - & 0.014 & 0.109 \\
\hline 948 & & & & & 0.003 & 0.191 & & & & & 0.032 & 0.123 \\
\hline \multicolumn{13}{|l|}{ APO2 } \\
\hline $102,888^{b}$ & - & - & - & - & 0.007 & 0.123 & - & - & - & - & 0.012 & 0.112 \\
\hline \multicolumn{13}{|l|}{ DEP1 } \\
\hline 41 & 0.003 & 0.053 & - & - & - & - & 0.035 & 0.038 & - & - & - & - \\
\hline $314^{c}$ & 0.011 & 0.039 & - & - & - & - & 0.005 & 0.064 & - & - & - & - \\
\hline $683,970^{c}$ & 0.006 & 0.060 & - & - & - & - & 0.004 & 0.089 & - & - & - & - \\
\hline \multicolumn{13}{|l|}{ FON1 } \\
\hline 1062 & 0.045 & 0.036 & - & - & - & - & 0.024 & 0.056 & - & - & - & - \\
\hline \multicolumn{13}{|l|}{ HD1 } \\
\hline 10 sites in $L D^{d}$ & - & - & 0.001 & 0.089 & - & - & - & - & 0.011 & 0.070 & - & - \\
\hline 646 & - & - & 0.006 & 0.064 & - & - & - & - & 0.012 & 0.067 & - & - \\
\hline 652 & - & - & 0.015 & 0.052 & - & - & - & - & 0.010 & 0.071 & - & - \\
\hline 660 & - & - & 0.005 & 0.088 & - & - & - & - & 0.012 & 0.093 & - & - \\
\hline 1216 & - & - & 0.005 & 0.068 & 0.001 & 0.185 & - & - & 0.023 & 0.057 & 0.039 & 0.078 \\
\hline \multicolumn{13}{|l|}{ SP1 } \\
\hline $922,983^{e}$ & - & - & - & - & 0.001 & 0.170 & - & - & - & - & 0.008 & 0.126 \\
\hline
\end{tabular}

a, 11 sites in complete LD: $40,57,537,546,627,765,795,850,951,1005,1188$; d, 10 sites in complete LD: 248, 249, 440, 466, 469, 487, 512, 661, 1062, 1324 $\mathrm{a}, \mathrm{b}, \mathrm{c}, \mathrm{d}$, and ${ }^{\mathrm{e}}$ were in complete LD

classified as favorable or unfavorable allele (Table 3). UPGMA cluster analysis divided allele combinations into four clusters according to polymorphic sites with consistent effects on phenotypic variation in both years (Fig. 4a). Cluster A, 74\% of which were japonica, carried an average of 5.7 favorable alleles. Cluster B was represented by indica varieties (66.7\%) and had seven favorable alleles on average. Cluster $\mathrm{C}$ contained four indica and three tong-il varieties and had the largest number of favorable alleles (12 alleles on average). The lowest average number of favorable alleles (4.5) was found in Cluster D. The average SPP value for each cluster was proportional to the number of favorable alleles, and SPP for Cluster $\mathrm{C}$ was higher than for other clusters (Fig. 4b).

\section{Discussion}

Characterizing the genetic diversity underlying agronomic traits provides evolutionary context and uncovers beneficial sequence variants that can be used to improve crop varieties. Understanding the relation between specific alleles and phenotypic variation facilitates the development of effective markers for use in rice breeding programs [12]. In this study, nucleotide and haplotype diversity of ten genes involved in panicle development were analyzed. Different patterns of sequence variation were observed in the coding regions of these genes. APO2 exhibited high levels of nucleotide diversity and relatively low haplotype diversity, as characterized by high LD between polymorphic sites $(71.8 \%$ of pairs of polymorphic sites) (Fig. 3b). By contrast, numerous rare polymorphisms in DEP1, FON1, and GN1a (Table 1) led to the construction of several rare haplotypes and few common haplotypes, resulting in low nucleotide diversity and high haplotype diversity for these genes. Neutrality tests were performed for eight of the ten genes (all except $L A X 1$ and MOC1). Deviation from neutrality was represented using Tajima's $D$ statistic. Significantly positive estimates of Tajima's $D$ were detected only for $A P O 2, F O N 1$, and $H D 1$. No significant deviation from neutrality was detected in the other genes, indicating that population subdivision events or balancing selection occurred at those loci during evolutionary and breeding processes (Table 1). Of the genes examined, the least polymorphism was detected in the $L A X 1$ coding region, with only a single SNP (Table 1). The high degree of sequence conservation in $L A X 1$ was detected across the indica, japonica, and tong-il varieties and was thus suggestive of strong selection at the $L A X 1$ locus during rice breeding. 
Table 3 Estimates of the allelic effect for phenotypic variation

\begin{tabular}{|c|c|c|c|c|c|c|c|}
\hline \multirow{2}{*}{$\begin{array}{l}\text { Position } \\
\text { (Position } \\
\text { (bp) }\end{array}$} & \multirow[t]{2}{*}{ Allele } & \multicolumn{3}{|c|}{2013} & \multicolumn{3}{|c|}{2014} \\
\hline & & $\mathrm{PL}$ & PB & SB & $\mathrm{PL}$ & PB & SB \\
\hline \multicolumn{8}{|l|}{ APO1 } \\
\hline \multirow[t]{2}{*}{$40^{\mathrm{a}}$} & $A$ & - & - & 14.4 & - & - & 9.9 \\
\hline & G & - & - & 0.0 & - & - & 0.0 \\
\hline \multirow[t]{3}{*}{948} & $C$ & - & - & 8.9 & - & - & 15.5 \\
\hline & DEL & - & - & 14.6 & - & - & 9.8 \\
\hline & A & - & - & 0.0 & - & - & 0.0 \\
\hline \multicolumn{8}{|l|}{ APO2 } \\
\hline \multirow[t]{2}{*}{$102^{b}$} & G & - & - & 13.2 & - & - & 11.1 \\
\hline & A & - & - & 0.0 & - & - & 0.0 \\
\hline
\end{tabular}

$\begin{array}{llllllll}\text { DEP1 } & & & & & & & \\ 41 & \text { A } & 5.7 & - & - & 4.3 & - & - \\ & \text { G } & 0.0 & - & - & 0.0 & - & - \\ 314^{c} & \text { A } & -7.4 & - & - & -8.5 & - & - \\ & \text { G } & 0.0 & - & - & 0.0 & - & - \\ 683^{c} & \text { T } & 4.2 & - & - & 4.1 & - & - \\ & \text { A } & 11.5 & - & - & 12.5 & - & - \\ & \text { DEL } & 0.0 & - & - & 0.0 & - & -\end{array}$

FON1

$\begin{array}{llllllll}1062 & C & -1.3 & - & - & -1.2 & - & - \\ & G & 0.0 & - & - & 0.0 & - & -\end{array}$

HD1

\begin{tabular}{|c|c|c|c|c|c|c|c|}
\hline \multirow[t]{2}{*}{$247^{d}$} & $\mathrm{G}$ & - & 2.1 & - & - & 1.9 & - \\
\hline & A & - & 0.0 & - & - & 0.0 & - \\
\hline \multirow[t]{2}{*}{646} & G & - & 1.9 & - & - & 2.0 & - \\
\hline & DEL & - & 0.0 & & - & 0.0 & - \\
\hline \multirow[t]{2}{*}{652} & G & - & 1.9 & - & - & 2.3 & - \\
\hline & DEL & - & 0.0 & - & - & 0.0 & - \\
\hline \multirow[t]{3}{*}{660} & $C$ & - & 1.2 & - & - & 1.7 & - \\
\hline & G & - & 2.7 & - & & 2.9 & - \\
\hline & DEL & & 0.0 & - & - & 0.0 & - \\
\hline \multirow[t]{2}{*}{1216} & $A$ & - & -1.8 & -11.9 & - & -1.7 & -6.8 \\
\hline & DEL & & 0.0 & 0.0 & - & 0.0 & 0.0 \\
\hline
\end{tabular}

SP1

$922^{e}$

\begin{tabular}{lllllll}
$\mathrm{G}$ & - & - & -10.5 & - & - & -8.0 \\
$\mathrm{~A}$ & - & - & 0.0 & - & - & 0.0 \\
\hline
\end{tabular}

a 11 sites in complete LD: $40,57,537,546,627,765,795,850,951,1005,1188$; $^{\text {b }}$ complete LD with 888 ; ${ }^{\mathrm{c}}$, complete LD with $970 ;{ }^{\mathrm{d}}, 10$ sites in complete LD: 248 , $249,440,466,469,487,512,661,1062,1324$; ${ }^{\text {, }}$ complete LD with 983

The SCM2 allele of APO1, which was isolated from 'Habataki', a high-yielding Japanese indica variety, increased SPP. 'Koshihikari' near isogenic lines (NILs) introgressed with SCM2 showed significantly increased spikelet numbers and grain yield, indicating that the allele could improve yield in japonica varieties [33]. In this study, the APO1-3 haplotype, which was identical to SCM2, was detected only in indica and tong-il accessions. Tong-il type varieties, which were derived from crosses between indica and japonica varieties developed in Korea, exhibited longer panicles, thicker neck nodes, and higher numbers of total rachis branches than japonica varieties [34]. Our results thus suggested that APO13 was introgressed from indica to tong-il type and was artificially selected as a beneficial haplotype during cross breeding between subspecies. In addition, similar patterns were detected in APO2-3, FON1-4, and SP1-5. With the exception of 'Hanmaeum', which exhibited the lowest SPP among the tong-il type varieties, all tong-il type varieties carried the same indica-derived haplotypes (Fig. 2). This result implies that these haplotypes, namely, APO1-3, APO2-3, FON1-4, and SP1-5, are preferred in tong-il type varieties and could contribute to the development of high-yielding varieties in crosses between indica and japonica rice cultivars.

Candidate gene association analysis is an effective way to identify favorable alleles for target traits. This approach has been extensively applied to discovering sequence variants associated with many rice traits, such as plant height, flowering time, spikelet number [14], disease resistance [35], and starch characteristics [36, 37]. Comprising association panel with a wide range of phenotypic variations is important to have enough statistical power to detect associated variants. Despite relatively small sample size, several previous studies successfully identified the variants associated with grain quality [38], eating and cooking qualities [39], salt stress resistance [40, 41], and high temperature stress tolerance [42] by using association panel displaying a wide range of phenotypic variations.

In this study, using 45 selected from 205 rice varieties which fully representing phenotypic variation for panicle size, associations between panicle-related traits (PL, PB, and $\mathrm{SB}$ ) and allelic variants were assessed to identify beneficial sequence polymorphisms with the potential to improve SPP. To reduce the risk of false positive association, we evaluated population structure with admixture model. Estimated Q matrix was used as covariate for the GLM association analysis. In addition, we only used common sequence variants to detect true association, removing minor sequence variants less than MAF $5 \%$.

Five, fourteen, and sixteen polymorphic sites in coding region were significantly associated with $\mathrm{PL}, \mathrm{PB}$, and $\mathrm{SB}$, respectively. Some of these sites, however, could not directly affect phenotype. These polymorphic sites can be interpreted as a result of strong LD with trait-related sequence variants [43]. For example, 11 polymorphic sites in complete LD in the APO1 coding region were significantly associated with SB. Of these, only two nonsynonymous SNPs located at $40 \mathrm{bp}$ and $765 \mathrm{bp}$, and two INDELs located at $850 \mathrm{bp}$ and 1188 bp position led to 


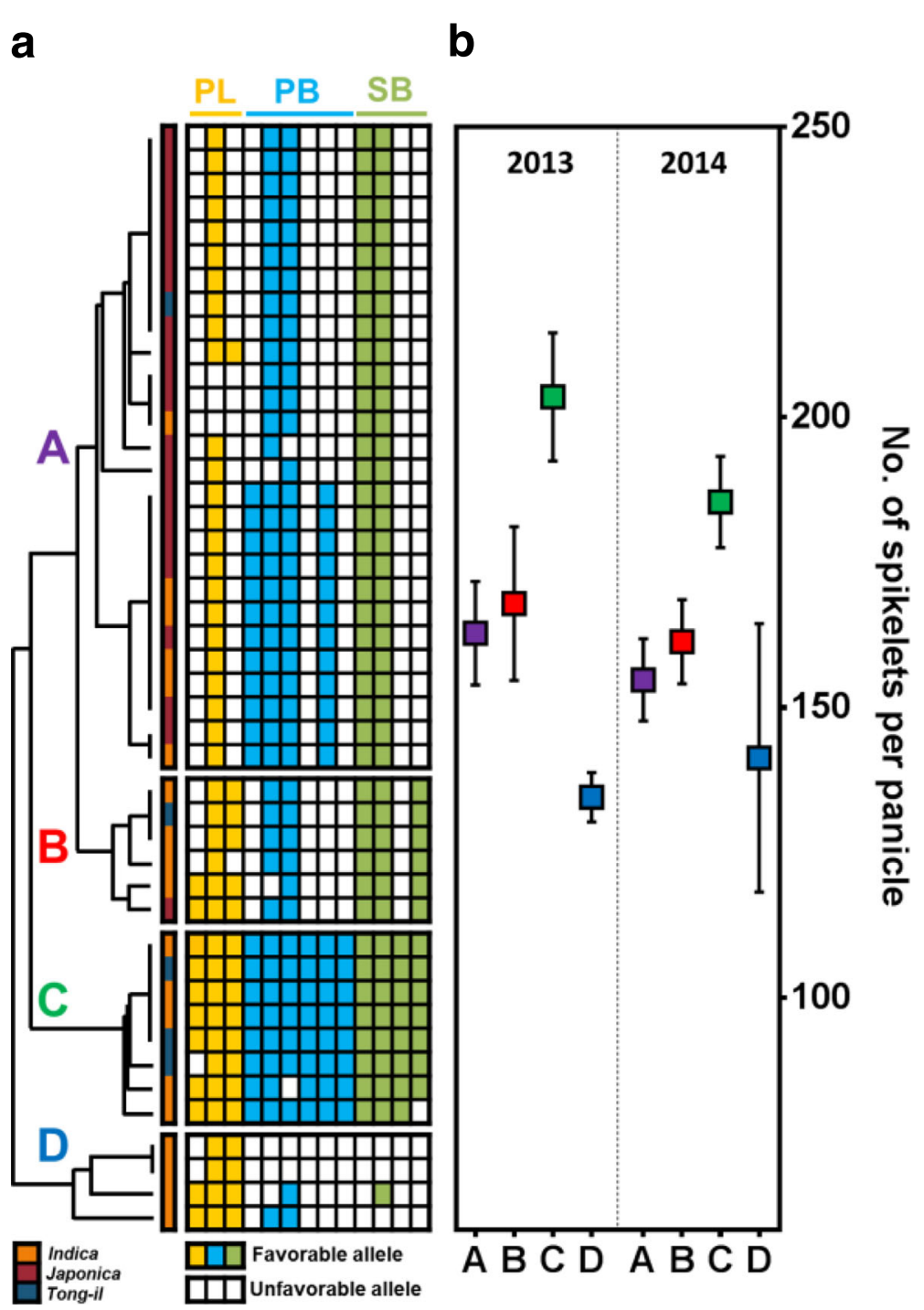

Fig. 4 Unweighted Pair Group Method with Arithmetic Mean (UPGMA) cluster analysis. a Allele combinations associated with panicle-related traits were divided into four clusters. Colors indicate favorable alleles for panicle-related traits: yellow, PL; sky blue, PB; yellow-green, SB. b Comparisons of average SPP values between clusters for 2 years (mean \pm SEM)

amino acid sequence changes and were thus likely to affect SB phenotypic variation.

In the HD1 coding region, four polymorphic sites, including two large INDEL regions of $129 \mathrm{bp}$ and $33 \mathrm{bp}$, and a small 4 bp INDEL causing a frameshift, were significantly associated with $\mathrm{PB}$. The 4 bp INDEL was also associated with SB under natural long-day conditions in the experimental field in Suwon, South Korea $\left(37^{\circ} \mathrm{N}\right.$ latitude). These results were consistent with previous reports revealing that large INDELs and small frameshift-inducing INDELs led to partial or complete loss of $H D 1$ function [15, 44]. Nine non-synonymous SNPs in complete LD in HD1 were also significantly associated with PB. These SNPs could be attributed to change of HD1 protein function as they substituted several amino acid sequence. However, it was unclear whether phenotypic variation was due to altered protein function from amino acid substitutions or to strong LD $\left(r^{2}=0.91\right)$ with an 2 bp INDEL inducing loss of function, located at $1000 \mathrm{bp}$ (Fig. 3e). Further studies are required to establish the role of the nine non-synonymous SNPs in determining phenotypic variation in PB.

UPGMA cluster analysis classified favorable allele combinations into four clusters (Fig. 4a). Varieties containing the highest number of favorable alleles were located in Cluster C. Varieties in this cluster also exhibited higher SPP values for two field test than varieties from the other three clusters (Fig. 4b). This result suggests that stacking and combining favorable alleles for three panicle-related traits can contribute to increases in SPP 
even though each individual allele has a relatively minor effect on phenotype (Table 3). Accordingly, the favorable alleles identified in this study can each be used as resource of functional markers in molecular breeding programs for improving SPP. Furthermore, combining favorable alleles from multiple genes has the potential to produce greater breeding improvements than using single favorable alleles alone.

\section{Conclusions}

A total of 142 polymorphic sites, which constructed 58 haplotypes, were detected in coding regions of several genes involved in panicle development. Thirty-five sequence variants of six genes that were significantly associated with panicle-related traits influenced SPP. Although each of the associated alleles explained relatively small amounts of phenotypic variation, a group of cultivars carrying higher numbers of favorable alleles exhibited higher SPP values on average than groups with fewer favorable alleles. This result implies that SPP could be increased by stacking favorable alleles for panicle-related traits. The favorable alleles identified in this study can therefore be used as resource for functional markers, and stacking favorable alleles could contribute to SPP improvement in rice breeding programs.

\section{Additional files}

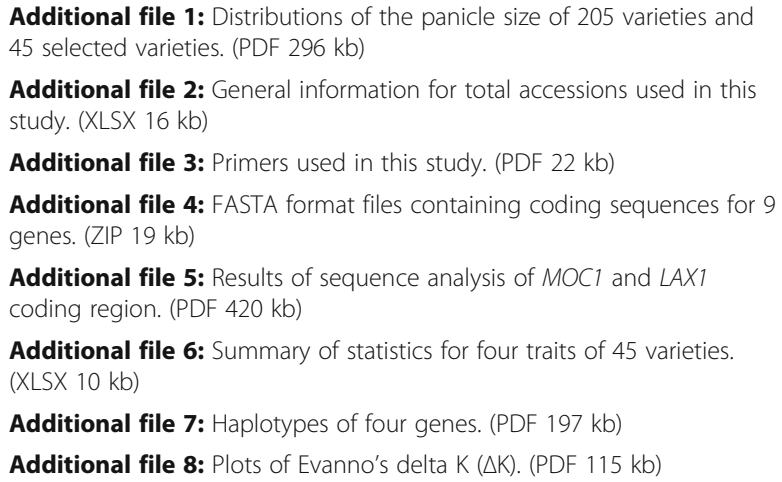

Additional file 2: General information for total accessions used in this study. (XLSX 16 kb)

Additional file 3: Primers used in this study. (PDF $22 \mathrm{~kb}$ )

Additional file 4: FASTA format files containing coding sequences for 9 genes. (ZIP $19 \mathrm{~kb}$ )

Additional file 5: Results of sequence analysis of MOC1 and $L A X 1$ coding region. (PDF $420 \mathrm{~kb}$ )

Additional file 6: Summary of statistics for four traits of 45 varieties. (XLSX $10 \mathrm{~kb}$ )

Additional file 7: Haplotypes of four genes. (PDF $197 \mathrm{~kb}$ )

Additional file 8: Plots of Evanno's delta $K(\Delta K)$. (PDF $115 \mathrm{~kb})$

\section{Abbreviations \\ GLM: General Linear Model; LD: Linkage disequilibrium; MAF: Minor allele frequency; NIL: Near isogenic line; PB: The number of primary branches per panicle; PL: Panicle length; SB: The number of secondary branches per panicle; SPP: The number of spikelets per panicle; UPGMA: Unweighted Pair Group Method with Arithmetic Mean}

\section{Funding}

This work was supported by a grant from the Next-Generation BioGreen 21 Program (Plant Molecular Breeding Center, No. PJ013165), Rural Development Administration, Republic of Korea.

\section{Authors' contributions}

HJK and JHC coordinated the project, and JS carried out sequencing and sequence analysis, and prepared the manuscript. YJL and GUL performed statistical analysis and association analysis. JHS and DRL provided DNA samples and allele-specific marker data. YYY provided phenotypic data. All authors read and approved the final manuscript.

\section{Ethics approval and consent to participate}

The source of all plant materials used in this research were collected and maintained in agriculture genetic resource center at Seoul National University. Plants were grown in the experimental field of Seoul National University following the conventional management.

\section{Consent for publication}

Not applicable.

\section{Competing interests}

The authors declare that they have no competing interests.

\section{Publisher's Note}

Springer Nature remains neutral with regard to jurisdictional claims in published maps and institutional affiliations.

Received: 26 June 2017 Accepted: 20 December 2017

Published online: 15 January 2018

References

1. Ando T, Yamamoto T, Shimizu T, Ma XF, Shomura A, Takeuchi Y, et al. Genetic dissection and pyramiding of quantitative traits for panicle architecture by using chromosomal segment substitution lines in rice. Theor Appl Genet. 2008;116:881-90.

2. Ikeda K, Ito M, Nagasawa N, Kyozuka J, Nagato Y. Rice ABERRANT PANICLE ORGANIZATION 1, encoding an F-box protein, regulates meristem fate. Plant J. Cell Mol. Biol. 2007;51:1030-40.

3. Ikeda-Kawakatsu K, Maekawa M, Izawa T, Itoh J-I, Nagato Y. ABERRANT PANICLE ORGANIZATION 2/RFL, the rice ortholog of Arabidopsis LEAFY, suppresses the transition from inflorescence meristem to floral meristem through interaction with APO1. Plant J Cell Mol Biol. 2012;69:168-80.

4. Ashikari M, Sakakibara H, Lin S, Yamamoto T, Takashi T, Nishimura A, et al. Cytokinin Oxidase regulates Rice grain production. Science. 2005;309:741-5.

5. Huang X, Qian Q, Liu Z, Sun H, He S, Luo D, et al. Natural variation at the DEP1 locus enhances grain yield in rice. Nat Genet. 2009:41:494-7.

6. Yan W-H, Wang P, Chen H-X, Zhou H-J, Li Q-P, Wang C-R, et al. A major QTL, Ghd8, plays Pleiotropic roles in regulating grain productivity, plant height, and heading date in Rice. Mol Plant. 2011;4:319-30.

7. Endo-Higashi N, Izawa T. Flowering time genes heading date 1 and early heading date 1 together control panicle development in Rice. Plant Cell Physiol. 2011;52:1083-94.

8. Suzaki T, Sato M, Ashikari M, Miyoshi M, Nagato Y, Hirano H-Y. The gene FLORAL ORGAN NUMBER1 regulates floral meristem size in rice and encodes a leucine-rich repeat receptor kinase orthologous to Arabidopsis CLAVATA1. Dev Camb Engl. 2004;131:5649-57.

9. Li S, Qian Q, Fu Z, Zeng D, Meng X, Kyozuka J, et al. Short panicle1 encodes a putative PTR family transporter and determines rice panicle size. Plant J Cell Mol Biol. 2009:58:592-605.

10. Oikawa T, Kyozuka J. Two-step regulation of LAX PANICLE1 protein accumulation in Axillary Meristem formation in Rice. Plant Cell. 2009;21:1095-108.

11. Komatsu K, Maekawa M, Ujiie S, Satake Y, Furutani I, Okamoto H, et al. LAX and SPA: major regulators of shoot branching in rice. Proc Natl Acad Sci U S A. 2003:100:11765-70

12. Lestari P, Lee G, Ham T-H, Reflinur N, Woo M-O, Piao R, et al. Single nucleotide polymorphisms and haplotype diversity in rice sucrose synthase 3. J Hered. 2011;102:735-46.

13. Xue $W$, Xing $Y$, Weng $X$, Zhao $Y$, Tang $W$, Wang $L$, et al. Natural variation in Ghd7 is an important regulator of heading date and yield potential in rice. Nat Genet. 2008:40:761-7.

14. Lu L, Yan W, Xue W, Shao D, Xing Y. Evolution and association analysis of Ghd7 in rice. PLoS One. 2012;7:e34021.

15. Wei X, Qiao W, Yuan N, Chen Y, Wang R, Cao L, et al. Domestication and association analysis of $\mathrm{Hd} 1$ in Chinese mini-core collections of rice. Genet Resour Crop Evol. 2013;61:121-42.

16. Edae EA, Byrne PF, Manmathan H, Haley SD, Moragues M, Lopes MS, et al Association mapping and nucleotide sequence variation in five drought tolerance candidate genes in spring wheat. Plant Genome. 2013;6:0.

17. Murray MG, Thompson WF. Rapid isolation of high molecular weight plant DNA. Nucleic Acids Res. 1980;8:4321-6.

18. Untergasser A, Nijveen $H$, Rao X, Bisseling T, Geurts R, Leunissen JA. Primer3Plus, an enhanced web interface to Primer3. Nucleic Acids Res. 2007;35:W71-4. 
19. You FM, Huo N, YQ G, Luo M-C, Ma Y, Hane D, et al. BatchPrimer3: a high throughput web application for PCR and sequencing primer design. BMC Bioinformatics. 2008:9:253.

20. Sakai H, Lee SS, Tanaka T, Numa H, Kim J, Kawahara Y, et al. Rice annotation project database (RAP-DB): an integrative and interactive database for rice genomics. Plant Cell Physiol 2013;54:e6-e6.

21. Thompson JD, Higgins DG, Gibson TJ. CLUSTAL W: improving the sensitivity of progressive multiple sequence alignment through sequence weighting, position-specific gap penalties and weight matrix choice. Nucleic Acids Res. 1994;22:4673-80.

22. Hall TA. BioEdit: a user-friendly biological sequence alignment editor and analysis program for windows 95/98/NT. Nucleic Acids Symp Ser. 1999;41: 95-8.

23. Librado P, Rozas J. DnaSP v5: a software for comprehensive analysis of DNA polymorphism data. Bioinformatics. 2009;25:1451-2.

24. Tajima F. Statistical method for testing the neutral mutation hypothesis by DNA polymorphism. Genetics. 1989;123:585-95.

25. Clement M, Posada D, Crandall KA. TCS: a computer program to estimate gene genealogies. Mol Ecol. 2000;9:1657-9.

26. Bradbury PJ, Zhang Z, Kroon DE, Casstevens TM, Ramdoss Y, Buckler ES. TASSEL: software for association mapping of complex traits in diverse samples. Bioinformatics. 2007;23:2633-5.

27. Pritchard JK, Stephens M, Donnelly P. Inference of population structure using multilocus genotype data. Genetics. 2000;155:945-59.

28. Evanno G, Regnaut S, Goudet J. Detecting the number of clusters of individuals using the software STRUCTURE: a simulation study. Mol Ecol. 2005;14:2611-20.

29. Earl DA, others. STRUCTURE HARVESTER: a website and program for visualizing STRUCTURE output and implementing the Evanno method. Conserv Genet Resour 2012:4:359-361.

30. Jakobsson M, Rosenberg NA. CLUMPP: a cluster matching and permutation program for dealing with label switching and multimodality in analysis of population structure. Bioinformatics. 2007;23:1801-6.

31. Wang J, Xu H, Li N, Fan F, Wang L, Zhu Y, et al. Artificial selection of Gn1a plays an important role in improving Rice yields across different ecological regions. Rice. 2015;8:37.

32. Zhang J, Zhou X, Yan W, Zhang Z, Lu L, Han Z, et al. Combinations of the Ghd7, Ghd8 and Hd1 genes largely define the ecogeographical adaptation and yield potential of cultivated rice. New Phytol. 2015;208:1056-66.

33. Ookawa T, Hobo T, Yano M, Murata K, Ando T, Miura H, et al. New approach for rice improvement using a pleiotropic QTL gene for lodging resistance and yield. Nat Commun. 2010;1:132

34. Park HS, Kim KY, Mo YJ, Choung JI, Kang HJ, Kim BK, et al. Characteristics of panicle traits for 178 Rice varieties bred in Korea. Korean J Breed Sci. 2010; 37(1):43-8.

35. Lee J-H, Muhsin M, Atienza GA, Kwak D-Y, Kim S-M, De Leon TB, et al. Single nucleotide polymorphisms in a gene for translation initiation factor (elF4G) of rice (Oryza Sativa) associated with resistance to Rice tungro spherical virus. Mol Plant-Microbe Interact. 2010;23:29-38.

36. Larkin PD, Park WD. Association of waxy gene single nucleotide polymorphisms with starch characteristics in rice (Oryza Sativa L.). Mol Breed. 2003;12:335-9.

37. Bao JS, Corke H, Sun M. Nucleotide diversity in starch synthase lla and validation of single nucleotide polymorphisms in relation to starch gelatinization temperature and other physicochemical properties in rice (Oryza Sativa L.). Theor Appl Genet. 2006;113:1171-83.

38. Chen L, Yan X, Wang L, Gao W, Yang J, Chen S, et al. Pasting properties, grain-filling characteristics and allelic variation linked to the grain quality in diverse rice. Euphytica. 2017;213

39. Tian Z, Qian Q, Liu Q, Yan M, Liu X, Yan C, et al. Allelic diversities in rice starch biosynthesis lead to a diverse array of rice eating and cooking qualities. Proc Natl Acad Sci. 2009;106:21760-5.

40. Kordrostami M, Rabiei B, Hassani Kumleh H. Association analysis, genetic diversity and haplotyping of rice plants under salt stress using SSR markers linked to SalTol and morpho-physiological characteristics. Plant Syst Evol. 2016;302:871-90.

41. Negrão S, Cecília Almadanim M, Pires IS, Abreu IA, Maroco J, Courtois B, et al. New allelic variants found in key rice salt-tolerance genes: an association study. Plant Biotechnol J. 2013;11:87-100.

42. Pradhan SK, Barik SR, Sahoo A, Mohapatra S, Nayak DK, Mahender A, et al. Population structure, genetic diversity and molecular marker-trait association analysis for high temperature stress tolerance in Rice. Prasad M. PLoS One. 2016;11:e0160027.

43. Brenner EA, Zein I, Chen Y, Andersen JR, Wenzel G, Ouzunova M, et al. Polymorphisms in O-methyltransferase genes are associated with stover cell wall digestibility in European maize (Zea Mays L.). BMC Plant Biol. 2010;10:27.

44. Yano M, Katayose $Y$, Ashikari M, Yamanouchi U, Monna L, Fuse T, et al. Hd1, a major photoperiod sensitivity quantitative trait locus in rice, is closely related to the Arabidopsis flowering time gene CONSTANS. Plant Cell. 2000; 12:2473-84.

\section{Submit your next manuscript to BioMed Central and we will help you at every step:}

- We accept pre-submission inquiries

- Our selector tool helps you to find the most relevant journal

- We provide round the clock customer support

- Convenient online submission

- Thorough peer review

- Inclusion in PubMed and all major indexing services

- Maximum visibility for your research

Submit your manuscript at www.biomedcentral.com/submit
) Biomed Central 